\title{
Miscellany
}

\section{Professor Helen Chiu}

Helen Chiu, a Fellow of the College, who is Chairman of the Department of Psychiatry at the Chinese University of Hong Kong and President of the Hong Kong College of Psychiatrists, has been awarded the Medal of Honour by the Hong Kong Special Administrative Region Government.

\section{New publications}

Following a seminar organised by the Mental Health Foundation, the Health Education Authority (HEA) has published a new guide entitled Promoting Mental Health: The Role of Faith Communities - Jewish and Christian Perspectives. Produced in partnership with the National Schizophrenia Fellowship, Churches Together in Britain and Ireland and the Jewish Association for the Mentally III, the guide covers a number of areas, including: the type of help and support that can be offered by religious communities and ways of tackling stigma; the relationship between mental health professionals and their service users with religious beliefs; and how faith can offer comfort, reassurance, guidance, support, a sense of belonging and can help to integrate people who have been ill into the community. At the same time, the Mental Health Foundation has published The Courage to Bare Our Souls. This new book, written by mental health service users, tells of the positive and negative impact that religion and spirituality have had on their lives. The HEA guide is available from HEA Customer Services (telephone: 01235 465565) and the book from the Mental Health Foundation (telephone: 0171 535 7441). Price: £7 for mental health service users and $£ 10$ for others.

Empowerment and Protection is the title of a new report published by the Foundation for People with Learning Disabilities, part of the
Mental Health Foundation. Written by Andy Alaszweski, Professor of Health Studies, School of Community and Health Studies, Hull University, the report looks at the stages needed to establish a risk policy and looks at examples of good practice. Although not recommending any one standard policy, the report examines how agencies can provide an effective balance between enabling people with learning disabilities to experience and learn from risk-taking and assuring their own and others' safety. It also stresses the importance of supporting staff following decisions made according to risk policy, of preparing for risks which may arise through unplanned events, and of learning from the decisions taken. Priced at £16, copies are available from the Mental Health Foundation (telephone: 0171535 7441).

The Sainsbury Centre for Mental Health has launched the following publications: Building a Partnership with Families Living with Schizophrenia (priced at £5) - a resource pack which provides a detailed guide to the family approach, psycho-education, family intervention and how to give practical support to carers; Developing an Integrated Mental Health Service (priced at £29) - a workbook aimed at those working within primary care groups which details the tasks that need to be completed to achieve excellent local services as well as providing information backing up these tasks; and A Complete Set of All the Current Executive Briefings Issued by the Sainsbury Centre (priced at \&3) - a set of nine executive briefings which covers most of the major policy issues in mental health which have arisen since 1998. For details of how to order and carriage charges, please contact the Sainsbury Centre for Mental Health, 134-138 Borough High Street, London SE1 1LB (telephone: 0171827 8351; fax: 0171403 9482). Pre-payment is needed for all orders under $£ 20$. 